\title{
SPECIFIC FEATURES OF STRUCTURE AND CONTENT OF THE PREPARATION FOR THE BULGARIAN NATIONAL RECORD OF ATHLETIC PENTATHLON (GIRLS UNDER 18)
}

\author{
Iva Dimova, Apostol Slavchev, Grigor Gutev, Petya Petkova \\ NSA"Vassil Levski", Sofia
}

\begin{abstract}
Summary
The current report provides profound study of structure and content of the preparation cycle of the current national record holder U18. The aim of the study is to reveal the specifics of the training model. The main tasks are: reveal the individual model of competition and the specifics of the sports training, concerning the structure and distribution of training means. The analysis is based on the orientation of the training methodical units, which are primarily related to the individual disciplines of athletic pentathlon. The ratio of the relative and absolute number of methodical units is revealed and we also present their dynamics over time. Total volume of used athletic means during the preparation period was also determined. The individualities of the record holder define the competitor as a jumper-runner type athlete, according to the given highest scores of the disciplines high jump and $800 \mathrm{~m}$ running using the IAAF scoring table. Estimating of specific features of structure and content of the training process reveals reserves for optimizing its characteristics in order to develop some parameters of the training model, according the given age and specific characteristics of the athlete. Such a parameter is the number of training sessions. Mainly one training session a day is made. With an appropriate increase of the number of sessions made, it will be possible to increase the number of methodical units in those pentathlon disciplines which have not been sufficiently affected in the training process, which will inevitably improve the sporting results.
\end{abstract}

Introduction

The current report provides profound study of structure and content of the preparation cycle of the current national record holder U18. The aim of the study is to reveal the specifics of the training model. The main tasks are: reveal the individual model of competition and the specifics of the sports training, concerning the structure and distribution of training means. The analysis is based on the orientation of the training methodical units, which are primarily related to the individual disciplines of athletic pentathlon. The ratio of the relative and absolute number of methodical units is revealed and we also present their dynamics over time. Total volume of used athletic means during the preparation period was also determined. The individualities of the record holder define the competitor as a jumper-runner type athlete, according to the given highest scores of the disciplines high jump and $800 \mathrm{~m}$ running using the IAAF scoring table. Estimating of specific features of structure and content of the training process reveals reserves for optimizing its characteristics in order to develop some parameters of the training model, according the given age and specific characteristics of the athlete. Such a parameter is the number of training sessions. Mainly one training session a day is made. With an appropriate increase of the number of sessions made, it will be possible to increase the number of methodical units in those pentathlon disciplines which have not been sufficiently affected in the training process, which will inevitably improve the sporting results.

AIM: To reveal the main directions and milestones determining the specificity of the training model when placing the pentathlon national record for girls under 18 years of age.

Objectives

1. To estimate the athlete's type according her competitive activity as a criteria.

2. Disclosing the specifics of the athlete's sports training process, conserning the structure and the distribution of the arsenal of used athletic means.

3. Establishing the type of the used athletic means according (special, specialized, auxiliary[5]).

Key words: pentathlon, national record, model of training,U18

Introduction

Penthathlon is an athletic discipline that combines disciplines from the group of running, jumping and throwing. Combined events are very interesting to watch and although a competitor is whether first, second or last in the different disciplines, the aims is to collect the maximum number of points that are determined by standardized scoreboards.
Without having mastered and improved the technique of any discipline, it is inconceivable to achieve high sporting results. While in individual track and field athletics disciplines in training and competitive activity are more concentrated and purpusfully, in combine events this effort is distributed into several directions. Moreover, the character of the pentathlon is a prerequisite for the emergence of com- 
plex situations in preparation of the athletes [6].

The training process in combined events is very complex, prolonged and very tiring for the athletes. Often, more than one discipline is combined in the training session so that the training methodology to be fully developed at the good level for all the five or seven events. In recent years, as methodological recommendations, athletes focus on disciplines in which the current athlete has greater potential for development. However, the controversial outcome largely depends on the mental and moral values of the athletes [1]. Key factors for selecting good combined eventsathletes are anthropometric indicators, age, endurance to heavy workloads, anteriorly development of force and technique in the later stages [2]. The pentathlon athletes are with very well-developed body, but still there are different types of athletes in the combined events, such as a runner type, jumper type, or a combined jumper-sprinter type and sprinter-thrower. Although these definitions are often used in training and competitive practice, they are not an exact criteria on which to classify individual types of competitors. According to Bäumler, a science-based system is needed to avoid inaccuracies and the use of pseudo-terms [3]. Scientific publications recommend that for the best profile of universal athletes to use a relationship with the world's elite and thus can be evaluated the most promising structure of athletes for realizing their full potential [4].

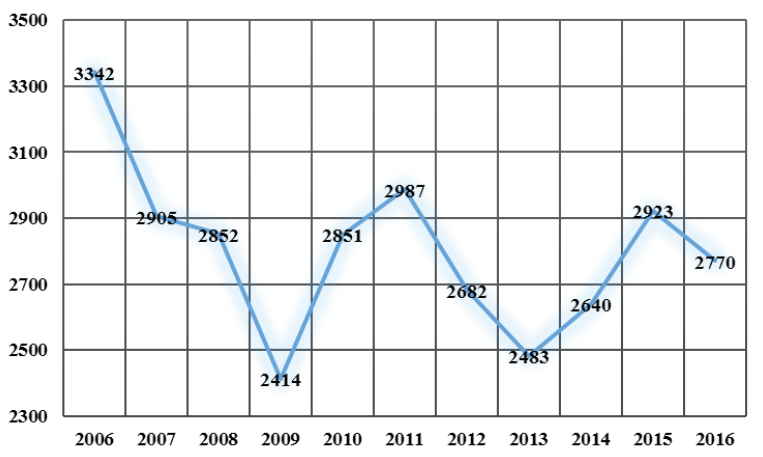

Figure №1 Dynamics of the sport results in the dicsipline for the period 2006-2016.

The competitor Iva Dimova managed to achieve an achievement of 3342 points in the pentathlon for girls under 18 years during the winter championships in 2006. The impressive number of points stays up to now, remaining unattainable for current athletes in one of the toughest athletic disciplines. Figure 1 depicts the dynamics of the sporting result in recent years since the year of the record - 2016.

\section{Methodology}

To achieve the goal and the tasks assigned for the current article, information from the competitor's training books was registered and analyzed through the record-breaking macrocycle. The following data was formulated from training book.

- Methodological units, denoted by numbers as follows for disciplines: 1-60 m; 2-high jump ; 3-shot put; 4-long jump; 5-800 m). The structure, duration and focus of the training process as well as the arsenal of training means for the realization of the given result, were established; Their dynamics over time also.

- Ratio of the absolute and relative number of methodological units;

- Number of training sessions;

- Set of athletic means

\section{Discussion and analysis}

The unbeatable result of the competitor has been preserved until 2016, when a new record was set, in 2017, but this was due to a slight change in evaluating achievements in the IAAF scoring tables, resulting in a new national record. The new record for the age group equals to 2932 points. But if we compare the athlete's achievements to this year's winner in the combined event, we see results that are weaker (Table 1). There is have superiority in 3 of the 5 disciplines. Nevertheless, I. Dimova's record remains in the history of track records at a national leve. Table 2 depicts the top 5 contestants in the year of placing the record, where the contestant is only beaten in two of the five disciplines - shot put and long jump. This is somehow explicable, because these two disciplines were not enough included in the training process (Figure 2).

Table № 1

\begin{tabular}{|c|l|c|l|c|c|c|c|c|c|}
\hline year & \multicolumn{1}{|c|}{ name } & & club & $\mathbf{6 0} \mathbf{~ m ~ h}$ & HJ & SP & LJ & $\mathbf{8 0 0} \mathbf{~ m}$ & points \\
\hline 2006 & IVA DIMOVA & $\mathbf{9 0}$ & Hebros-Harmanli & $\mathbf{9 , 9 6}$ & $\mathbf{1 7 1}$ & $\mathbf{8 , 3 2}$ & $\mathbf{4 , 8 5}$ & $\mathbf{2 : 2 0 , 5 7}$ & $\mathbf{3 3 4 2}$ \\
\hline 2017 & Viktoria Jordanova & 1 & SK Kostenec & 9,53 & 1,54 & 9,44 & 4,79 & $2: 49,61$ & 2932 \\
\hline
\end{tabular}


Table №2

Results of the first five athletes in the year of setting the national record for pentathlon

\begin{tabular}{|c|c|c|c|c|c|c|c|c|c|c|c|c|c|c|}
\hline & & & & \multicolumn{2}{|c|}{$60 \mathrm{~m}$ hurdles } & \multicolumn{2}{|c|}{ high jump } & \multicolumn{2}{|c|}{ shot put } & \multicolumn{2}{|c|}{ long jump } & \multicolumn{2}{|c|}{$800 \mathrm{~m}$} & \multirow[t]{2}{*}{ points } \\
\hline place & Name & & club & result & points & result & points & result & points & result & points & result & points & \\
\hline 1 & IVADIMOVA & 90 & Hebros-Harmanli & 9,96 & 720 & 171 & 867 & 8,32 & 420 & 4,85 & 519 & 2.20 .57 & 816 & 3342 \\
\hline 2 & Milena Mitkova & 90 & Levski-Sofia & 10,05 & 703 & 135 & 460 & 7,46 & 365 & 5,17 & 606 & 2.33 .34 & 652 & 2786 \\
\hline 3 & Aleksandra Ribarova & 90 & Dunav-Ruse & 10,38 & 643 & 147 & 588 & 8,90 & 458 & 4,94 & 543 & 2.58 .72 & 377 & 2609 \\
\hline 4 & Elina Georgieva & 89 & Athletic-Haskovo & 10,41 & 637 & 150 & 621 & 7,66 & 377 & 4,77 & 498 & 2.48 .84 & 476 & 2609 \\
\hline 5 & Maria Dundarova & 91 & Obosirshte-Panagiurishte & 10,90 & 553 & 141 & 523 & 7,36 & 358 & 3,98 & 303 & 2.59 .29 & 372 & 2109 \\
\hline
\end{tabular}

\section{RELATIVE SHARE OF METHODOLOGICAL UNITS}

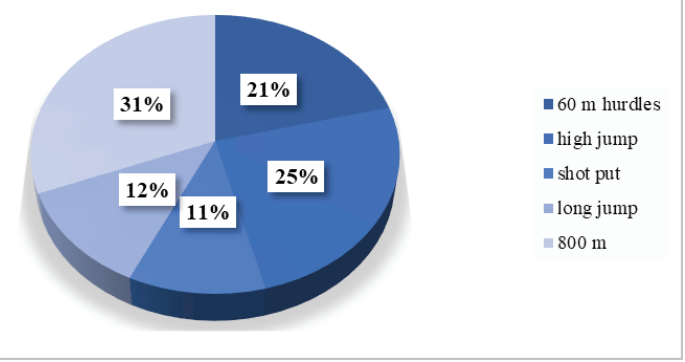

Figure № 2 Relative parts of methodological units though the whole training period

The structure of the competitor's preparation the competitor has done a total of 135 workouts, and consists of 1 macrocycle, which includes 5 meso- two training sessions a day being a rare occurrence. cycles. The training process lasts 22 training weeks The total set of athletic means used for each one of (from September to mid-February). During this time the disciplines in the pentathlon is 49 .

Table №3

Distribution of methodological units in mesocycle and microcycle during the preparation.

\begin{tabular}{|c|c|c|c|c|c|c|c|c|c|c|c|}
\hline \multicolumn{4}{|c|}{ septe mber } & \multicolumn{4}{|c|}{ october } & \multicolumn{4}{|c|}{ november } \\
\hline 1 & 2 & 3 & 4 & 5 & 6 & 7 & 8 & 9 & 10 & 11 & 12 \\
\hline 5 & 5 & 5 & 5,2 & 2,5 & 5 & 5,2 & $2,1,5$ & 2 & 5,3 & 2 & 2,5 \\
\hline 2,5 & 5 & 1,2 & 2,1 & 1,4 & 1,4 & 1 & 1 & 3,4 & 2,1 & 3 & 1 \\
\hline 5 & 1 & 1 & 8 & 5 & 5,2 & 5,2 & $1,3,5$ & 1 & 2 & 3,5 & 5 \\
\hline 5 & 2 & 5 & 1 & 1,4 & 1 & 1 & $1,3,2$, & 2,1 & 1 & 1 & 3,4 \\
\hline 4 & 4 & 5 & 2,3 & 4 & 5,2 & 5 & & 5 & 5 & & 4 \\
\hline 5 & & 2 & 4 & & 5 & 2,3 & & & & & \\
\hline \multicolumn{4}{|c|}{$\begin{array}{l}\text { MU per mesocycle: } 26 \\
\text { training sessions: } 23\end{array}$} & \multicolumn{4}{|c|}{$\begin{array}{l}\text { MU per mesocycle: } 32 \\
\text { training session: } 21\end{array}$} & \multicolumn{4}{|c|}{$\begin{array}{l}\text { MU per mesocycle: } 26 \\
\text { training session: } 19\end{array}$} \\
\hline \multicolumn{4}{|c|}{ december } & \multicolumn{4}{|c|}{ january } & \multicolumn{4}{|c|}{ february } \\
\hline 13 & 14 & 15 & 16 & 17 & 18 & 19 & 20 & 21 & 22 & & \\
\hline 4,5 & 3,5 & 3,5 & 1,2 & 2,5 & 1,4 & 5 & 5 & 5 & 5 & & \\
\hline 1,2 & 5 & 2 & 5 & 1 & 5,1 & 1 & 1,2 & 1,2 & 4 & & \\
\hline 1,2 & 2 & 3,5 & 1 & 1,4 & 3,5 & 5,4 & 2 & 1 & 1 & & \\
\hline 5 & 5 & 2,1 & 2 & 2,1 & 2 & 1 & $2,3,5$ & 5 & 2,3 & & \\
\hline 3 & 3,5 & 5 & 2 & 1,2 & 2 & 2 & & 1,4 & & & \\
\hline \multicolumn{4}{|c|}{$\begin{array}{l}\text { MU per mesocycle: } 32 \\
\text { training session: } 20\end{array}$} & \multicolumn{4}{|c|}{$\begin{array}{c}\text { MU per mesocycle: } 30 \\
\text { training session: } 19\end{array}$} & \multicolumn{4}{|c|}{$\begin{array}{c}\text { MU per mesocycle: } 12 \\
\text { training session: } 9\end{array}$} \\
\hline
\end{tabular}

In Figure № 3 the absolute values of the orientation and December the work done marks its peak. In of training sessions according to the different November, we observed a drop in the values of disciplines in combined events are presented. all disciplines, except MU shot put, which slightly The lowest values were recorded in the long jump increased compared to the previous mesocycle. ranging between 2 to 4 times in the mesocycle. Undoubtedly the realized MU for 800 meters have Shot put also varies in low values, and in November the highest values. 


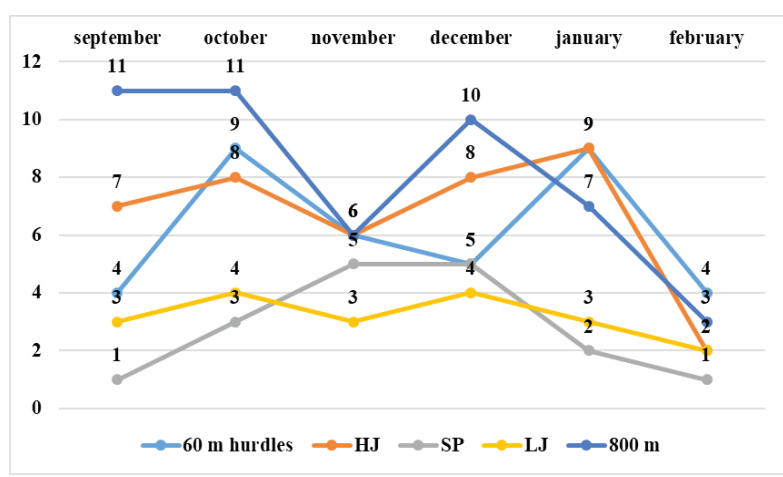

Figure № 3 Dynamics of methodological units distribution

The means used in the competitor's training, classified on the basis of similarity and the difference to the main competition exercise (Special (SPC) Specialized (SPC) and Auxilary (SMP)), are represented on Fig. 4 by their relative percentages. The largest share is justifiably received by special funds, which are equivalent to $47 \%$. Auxilary means are $33 \%$, specialized means have the lowest percentage value of $20 \%$.

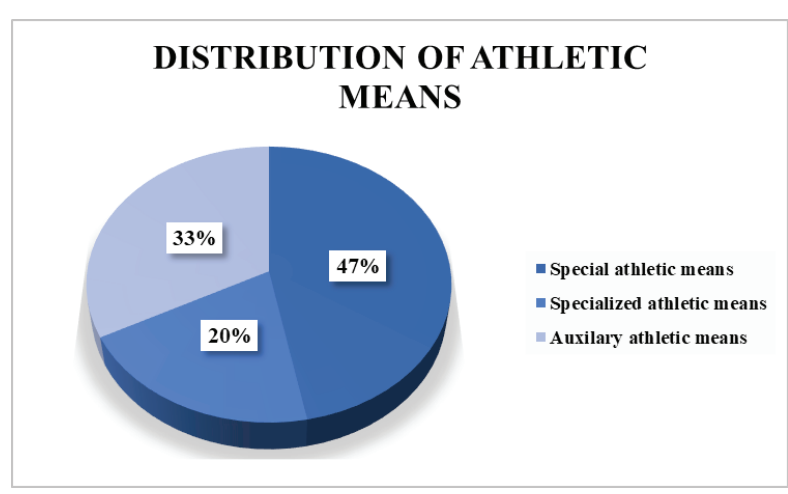

Figure №4 Distribution of the type of athletic means according to the theory Specialized diversity (М. Бъчваров)

\section{Conclusions:}

The competitor can be designated conditionally as a runner-jumper type, achieving highest scores in
800 meters and the high jump, and according to the IAAF scoring tables, the two achievements exceed the limit of 800 points. Sports achievements in the womens combined events in Bulgaria above this limit are not found among the other athletes, both in the year of record and in the years since then.

Concerning the content of the training preparation, we can claim that there are reservations about the number of training sessions. Adding same more second training session a day in the training process would definitely make it possible to increase the number of MU used, especially in disciplines which are less trained.

Thoroughly investigation of the content of the training preparation would provide further clarification on the specificity of the type of diversity of athletic means used, their volumetric values and their distribution during the sport training process. Such data would be of great scientific application value

\section{Refferences}

Bilić, M. Determination of taxonomic type structures of top decathlon athletes. Acta Kinesiologica 9(S1), 2023,2015.

Pavlović, R. et al., STRUCTURE OF THE ATHLETIC ALL-AROUND COMPETITION OF STUDENTS Ratko Acta Kinesiologica 10 Issue 2: 13-20,2016.

Stemmler, M. \& Bäumler, G. The Detection of Types among Decathletes using Configural Frequency Analysis (CFA). Psychology Science, 47(3-4), 447-466, 2005.

Wang, Z \& Lu, G. The Czech Phenomenon of Men's Decathlon development. International Journal of Sports Science and Engineering, 1(3), 209-214., 2007.

Бъчваров, Д., Тренировка в седмобоя за жени, София, 1984

Бъчваров, М. ,Спортология, София, 2000. 